\title{
Evaluation of Bacteriological Quality in Artisanal Juices Issued at Carabobo University. Faculty of Health Sciences. Bable Core
}

\section{Noja Izzeddin*, Arencibia R Angely, Barreto G Martha, Luís F Medina}

University of Carabobo, Venezuela

*Corresponding Author: Noja Izzeddin, University of Carabobo, Venezuela.
Received: October 19, 2020

Published: December 11, 2020

(C) All rights are reserved by Noja Izzeddin., et al.

\section{Abstract}

Foodborne diseases, most of which are of microbial origin, have a global impact as a major cause of morbidity and mortality; in this way the intake of contaminated food has become one of the most important ways to adapt gastrointestinal diseases. The objective of this work was to evaluate the bacteriological quality in artisanal juices of expended in the schools of Bioanalysis, Biomedical Sciences and Basic Area at the Faculty of Health Sciences of the Universidad de Carabobo headquarters Bárbula, in May 2015. The study was within the limits of descriptive, non-experimental and field research, as a total of 30 samples of artisanal fruit juices were collected and analyzed, which is evaluated at different times. For the analysis of juices, the quantification of total and heat-resistant coliform bacteria and the identification of bacteria such as Escherichia coli and Salmonella spp were performed. Of the 30 samples studied $60 \%$ had total coliforms, $33 \%$ had heat resistant bacteria, and the total samples did not identify the presence of Escherichia coli or Salmonella spp. Thus concluding that the presence of pathogenic microorganisms in the arts juices of frequent consumption in the schools Bioanalysis, Biomedical Sciences and Basic Area of the Faculty of Health Sciences, suggests that the health quality of these actually poses a risk to the health of consumers since feedings cannot contain microorganisms.

Keywords: Juices; Total Coliforms; Heat Resistants; Escherichia coli; Salmonella spp

\section{Introduction}

Foodborne diseases have a global impact as a major cause of morbidity and mortality. The WHO global health organization estimates that 1 in ten people worldwide are sick from eating contaminated food and that 420,000 die from the same cause [34]. It should be noted that Latin America has the second lowest burden of foodborne diseases worldwide. However, 77 million people still get sick annually from consuming contaminated food, and about 9,000 a year [36] of those people die.

Likewise, food provides the right nutrients for the growth of a wide variety of microorganisms that may be responsible for the breakdown of them and the transmission of pathogens or toxins. In this way the intake of contaminated food has become one of the most important ways to acquire gastrointestinal diseases, be- ing generally infectious or toxic in nature and are caused by toxins, viruses, parasites, fungi and bacteria. Most of these diseases are caused by bacteria such as Escherichia coli and Salmonella spp. which are among the most common foodborne pathogens affecting millions of people each year, sometimes con serious or fatal consequences [34] whose main cause is improper handling or lacking hygienic-sanitary conditions, such as the preparation and preservation thereof, the cleaning and insufficient disinfection of equipment used, physical deterioration when exposed to inadequate temperature and humidity conditions, and the use of unsuitable water [3].

The Salmonella Spp. characterized by being a gram-negative, non-fermenting bacillus of lactose, mobile with scourges (H antigen), aerobics and optional anaerobic, with an optimal growth temperature of $37^{\circ} \mathrm{C}$ and a $\mathrm{pH}$ between 6.8 and 7.6 [6] is pathogenic 
common in small animals (poultry, cows, pigs, pets, birds, sheep, among others), are the main source of non-typhoid salmonellosis in humans [7]. It is also one of the most common and widely spread foodborne diseases. It is usually characterized by high fever, abdominal pain, diarrhea, nausea and it's vomiting. People contract salmonellosis through the consumption of contaminated food of animal origin (mainly eggs, meat, birds and milk), although other foods have also been linked to transmission, including contamin vegetables and as for manure; can also be transmitted between people fecally-orally [33].

It is important to note that Escherichia coli normally inhabits the colon without causing disease, however, by genetic mechanisms of conjugation, exchange of plasmids with other enterobacteria, tempered bacteriophages, transformation, acquire virulence factors that make them pathogenic. They comprise microorganisms in a bacillary form, whose natural habitat is man's faeces, some annimales and the environment, reaching concentrations of $10^{9}$ bacteria per gram of faeces in humans. Escherichia coli can cause diarrhoeal diseases, urinary tract infections, sepsis, meningitis, intrahospital infections and intra-abdominal infections. Diarrhoeal diseases caused by E. coli are very common worldwide. Transmission of $E$. coli is caused by ingestion of water contaminated with faeces, contaminated food, lack of hygiene in food preparation or through flies [6].

In this way, research related to the subject studied has been developed, Rodríguez Rico y cols., 2012 determined the microbiological quality of refreshing beverages dispensed in machines of seven fast food restaurants in district one of the metropolitan area of San Salvador. In order to undermine safety in these beverages and to know the conditions in which the dispensing machines were located. They conclude that the results could be due to inadequate compliance with good hygiene practices, staff or dispensing machines [14].

On the other hand, Olvera Castelán, 2007 investigated the presence of microorganisms indicators of health quality in carrot juice, coming from different restaurants in the city of Pachuca de Soto, Mexico. Concluding that the frequency and levels with which thermotolerant coliforms were isolated, Escherichia coli and Salmonella spp showed external contamination in juices linking this factor to a high risk of gastrointestinal diseases [1].

In this same order of Gil and cols. ideas, 2010 evaluated the microbiological quality in edible shell fruits (strawberries, guavas and peaches) issued in popular markets in Valencia and San Diego, Carabobo state, Venezuela. They determined the number orUFC/g of aerobic mesophiles (MA), total and faecal coliforms (CT, CF) and Salmonella spp. according to COVENIN Standards. Of the fruits analyzed, strawberries had the highest degree of microbiological contamination by both MA and CT. The ausencia of CF and Salmonella spp suggested that the conditions to which the fruits were subjected during the pre- and post-harvest period were apparently within the permissible limits of health quality [13].

Likewise Rojas and cabbage. 2003 conducted a study in Venezuela where they evaluated the survival of an isolate of Escherichia coli 0157:H7 in non-pasteurized commercial expendio orange juices, obtaining data indicating the survival of the observed microorganism hasbeen for8 days post-inoculum, and in the first 4 days viable cell levels were found in the order of $10^{2}$ to $10^{4 \mathrm{CFus} / \mathrm{ml}}$ of juice [12].

Given the high incidence of gastrointestinal disorders related to the consumption of foods with taminates in the world and in Venezuela which is intensified by areas with high numbers of consumers such as the academic environment, the initiative arose to evaluate the bacteriological quality in artisanal juices issued in the cafetines of the UC Bárbula School of Health Sciences, and to determine whether they constituted a source of health risk knowing that it is an unpereurized food; and thus alert to the risks of diseases caused by Escherichia coli and Salmonella spp and provide valuable information in order to improve the quality of life of the students of the faculty.

\section{Materials and Methods}

This study was placed within the limits of descriptive, nonexperimental and field research, longitudinal cutting, as a total of 30 samples of artisanal fruit juices were collected and analyzed, which were evaluated at different times, issued at carabobo University Faculty of Health Bárbula headquarters which were collected through a simple random probabilistic method [27].

\section{Methodological procedure}

The processing of the samples began with the random collection of varieties of artisanal fruit juices issued in each of the schools(Bioanalysis, Biomedical Sciences and Basic Area) of the University of Carabobo Bárbula Headquarters. Once the samples were obtained, they were immediately transferred to the Center for Applied Microbiological Research (Cima-UC), Faculty of Health Sci- 
ences, Carabobo University, for immediate analysis. For the collection of juice sample data, a collection ficha was applied with date, fruit type, proven coffee and sample number.

\section{Sample collection}

For the production of samples, a total of 30 artisanal fruit juices were collected from each of the schools (Bioanalysis, Biomedical Sciences and Basic Area) of the University of Carabobo Bárbula Headquarters. For the research and identification of artisanal juice samples, microbiological analysis was used by the Venezuelan Food Standard COVENIN 1126-89 "Alimentos. Identification and preparation of samples for microbiological analysis". The samples were collected in appropriate sterile and pressure-covered containers appropriately identified with the date, type of fruit, proven coffee and sample number were subsequently reserved with cava cooling for transfer. Samples were analyzed as soon as possible [28].

\section{PH Determination (Ionic Acidity)}

The $\mathrm{pH}$ was determined in a $20 \mathrm{ml}$ aliquot of juice, previously mixed The through the potentiometric technique, pre-calibrated with distilled water [29].

\section{Detection of total and heat-resistant coliform bacteria}

To quantify total and heat resistant coliform bacteria in artisanal juices, the use of Petri Plates followed COVENIN 1086-84 "Food. Methods for counting Coliform bacteria in Petri Plates"; in the year the method consisted of mixing a certain volume of a representative and homogeneous sample of the juice examined with a culture medium (MacConkey agar) in Petri plates. After the incubation period, the number of colonies that pre-seated typical characteristics of coliform bacteria [30] was determined as the fermentation of lactose evidenced in MacConkey Agar by the presence of fuchsia-colored colonies. The procedure employs $1 \mathrm{ml}$ of the sample on each Petriboard with MacCon key Agar covering up for 24 hours at $37^{\circ} \mathrm{C}[30]$.

\section{Identification of Escherichia coli}

For the determination. of Escherichia coli MacConkey Agar was used which is a differential planting medium for the selection and recovery of Enterobacteriaceae and related enteric gram negative bacilli [31].

The possible presumptive colonies of $E$. coli were re-insulated with the help of a bacteriological handle on the surface of a nutri- ent agar, zigzagging (exhaustion). Bacterial cells were increasingly deposited along the handle's path. The plate was incubated at $37^{\circ} \mathrm{C}^{\circ}$ for 24 hours. From each deposited cell a colony [33] was formed.

\section{Confirmatory biochemical tests for Escherichia coli}

- $\quad$ Kligler (KIA): The medium (KIA) was prepared in a tube in a sloping position, then taking from the pure culture asingle colony with an inoculation needle the microorganism was inoculated by puncture of the bottom of the tube and by striation at the flute beak finally incubated at $37^{\circ} \mathrm{C}^{\circ}$ for 24 hours [35].

- Sulfuro-indol mobility (SIM): This test is a semi-acid agar sown in profundity which was performed by taking with a bacteriological handle a colony of the nutrient agar and sowing by puncture only once at a depth of only 0.8 to $1.2 \mathrm{~cm}$ in the center of the tube and then incubating at $37^{\circ} \mathrm{C}^{\circ}$ for 24 hours [34].

Indol: This test was performed using approximately $0.5 \mathrm{ml}$ of the Kovac reagent whose positive result for Escherichia coli was demonstrated by a red ring; resulting in no color change following the addition of reactivor [34].

- Mobility test: This test was performed to determine whether a microorganism is mobile whose positive result for Escherichia coli was visualized with the spread of the bacteria in the medium in the radial direction from the planting site; Iremaina negative result that the microorganism remained motionless at the planting site [34].

- Hydrogen sulfide production: In this test the positive result was obtained the observation of a black precipitate at the bottom of the tube and as negativesulting for Escherichia coli no black precipitate [7].

- Citrate: In this test, a single colony was taken from pure cultivation with an inoculation needle sown by puncture at the bottom of the tube and by striation at the peak of flauta, then $s$ and incubated at $37^{\circ} \mathrm{C}$ for 24 hours observing as a positive result the development of blue indicating alkalization of the medium and as a negative result for Escherichia coli lack of growth [34].

- Urease: It was determined by erectinga bacterial suspension of a pure colony of the culture in nutrient agar and sembling it in the tube of the broth urease gently stirring and incubating at $37^{\circ} \mathrm{C}{ }^{\circ}$ for 24 hours, resulting in a pink-red coloration intenso throughout the broth and as a negative without color change (yellow-orange) [35]. 


\section{Salmonella spp detection}

To isolate and identify Salmonella spp. in artisanal juices, Petri Plates were used in accordance with COVENIN 1291-88. "Food. Salmonella Isolation and Identification"; in which it was precised from successive stages because the microorganism is usually in low number. The stages to be considered were [36].

\section{Pre-enrichment}

$20 \mathrm{ml}$ of the juice sample was measured, in an appropriate container previously tarded and added $180 \mathrm{ml}$ of the pre-enrichmentmedium which was the Lactose Broth is mixed or left at rest for approximately 1 hour at room temperature subsequently incubated the pre-enriched sample at $37^{\circ} \mathrm{C}$ for 24 hours [36].

\section{Enrichment}

After the incubation period, $1 \mathrm{ml}$ of the pre-enrichment broth culture was transferred to $10 \mathrm{ml}$ Tetrathionate Broth with the addition of Lugol to inhibit the accompanying flora and incubated from $35^{\circ} \mathrm{C}-36^{\circ} \mathrm{C}$ for 24 hours [36].

\section{Insulation}

At the end of 24 hours of incubation, a roast ( 3 to $5 \mathrm{~mm}$ ) of the previously homogenized selective enrichment medium was transferred to the surface of Salmonella - Shigella agar plates and incubated at a temperature of $37^{\circ} \mathrm{C}$ for 24 hours. At the end of the incubation were observed the presumptive colonies of Salmonella spp. whose characteristics in the differential medium are [36].

\section{Agar Salmonella-Shigella}

The growth of Salmonella spp. species is not inhibited and the colonies were colorless with black centers due to the production of hydrogen sulfide gas [31].

\section{Identification of presumptive colonies of Salmonella}

It was transferred with a handle 2 or more colonies typical of each selective medium in Kligler and Citrate Agar, doing inoculation in depth (by puncture) and on the surface following a longitudinal stroke the tubes were incubated at a temperature of $37^{\circ} \mathrm{C}$ for a period of 24 hours, observing the tubes at the end of theincubation fart. Crops suspected of being Salmonella Salmonella spp. showed the following reactions [36].

\section{Agar kligler}

Alkaline bezel, red (not fermenting lactose and/or sucrose) and yellow taco (acid reaction by fermentation of lglucose) with or without sulphurized hydrogen production that was manifested by total or partial blackening of the agar. Some Salmonellas Spp. sucrose and/or lactose can ferment and produce acidity (yellow) in both the taco and bezel [36].

\section{Citrate test}

For Salmonella spp. it was positive observing growth with an intense blue color on the flute beak. (The color change of the indicator was due to the production of acid or alkali by the microorganism under study when it grows in the middle [34].

\section{Immobilized sulfide-indoletest d (SIM)}

For Salmonella spp. the indole test was shown negative, positivo and positive for mobility and sulfide as a middle blackening [35] was observed.

Urease test

For Salmonella spp. it was shown negative without color changes (yellow-orange) [35].

\section{Results and Discussion}

The following table was obtained as a result of the $\mathrm{pH}$ measurement of artisanal juices produced in the schools of Bioanalysis, Biomedical Sciences and Basic Area of the University of Carabobo.

In the samples analyzed, the $\mathrm{pH}$ was determined in which it was possible to visualize that all artisanal juices had acidic $\mathrm{pH}$, in order to be preserved from microorganisms that could affect them and damage their composition, which could be observed with the $\mathrm{mu}(1,4,5,8,9,11,12,15,16,18,19,20)$ which had the most acidic $\mathrm{pH}$ compared to the $\mathrm{pH}$ scale, indicating that they were probably less prone to the growth of microorganisms. This determination was made in order to assess the degree of acidity of the juice samples to check whether or not they met the optimal $\mathrm{pH}(\mathrm{pH}-7)$ for bacterial growth.

Coliforms are short bacilli that have been defined as aerobic bacteria or optional anaerobics that ferment lactose with gas production. The main species of coliform bacteria are Escherichia coli and Enterobacter aerogenes; it does nothinder, the species that may meet these criteria, are more than twenty, being among the same species of other genera of the family Enterobacteriaceae and even species of Aeromonas. The group of fecal coliforms includes the Coliformes capable of growing at high temperature $\left(44.5^{\circ} \mathrm{C}\right.$ or $\left.45^{\circ} \mathrm{C}\right)$. The first objective of high-temperature incubation tests was the differentiation of coliforms of fecal origin from those without fecal origin. The use of "indicer" microorganisms was initiated with the determination of $E$. coli in water, as a substitute for the determination of Salmonella typhi. This concept is based on Shardingen's 
claim in 1892 that bacteria of species that ho and we call E. coli could be used as indexes or indicators of faecal contamination, as they could be more easily isolated than Salmonella spp species. Other groups of indicator bacteria and other tests devised or used include faecal or enterococcal streptococcals, Enterobacteriaceae, staph (indicating the possible presence of the enterotoxin of S. aureus or poor management), and the presence of Geotrichum candidum, the mold of the machines, as an indicator of the cleaning sting of the industrial plant or the degree of contamination of the equipment [15].

\begin{tabular}{|c|c|c|}
\hline Sample & Fruit & pH \\
\hline 1 & Afterranja & 3,09 \\
\hline 2 & Peach & 4,0 \\
\hline 3 & Soursop & 4,01 \\
\hline 4 & Strawberry & 3,06 \\
\hline 5 & Parchita & 3,05 \\
\hline 6 & Orange & 4,0 \\
\hline 7 & Soursop & 4,01 \\
\hline 8 & Parchita & 3,02 \\
\hline 9 & Strawberry & 3,06 \\
\hline 10 & Melon & 6,0 \\
\hline 11 & Orange & 3,8 \\
\hline 12 & Parchita & 3,3 \\
\hline 13 & Milky & 4,7 \\
\hline 14 & Melon & 5,7 \\
\hline 15 & Strawberry & 3,6 \\
\hline 16 & Strawberry & 3,5 \\
\hline 17 & Peach & 4,0 \\
\hline 18 & Soursop & 3,8 \\
\hline 19 & Orange & 3,7 \\
\hline 20 & Parchita & 3,3 \\
\hline 21 & Soursop & 5,0 \\
\hline 22 & Peach & 5,1 \\
\hline 23 & Orange & 4,5 \\
\hline 24 & Melon & 6,4 \\
\hline 25 & Parchita & 4,0 \\
\hline 26 & Soursop & 4,9 \\
\hline 27 & Parchita & 4,4 \\
\hline 28 & Melon & 6,2 \\
\hline 29 & Parchita & 4,0 \\
\hline 30 & Peach & 4,6 \\
\hline
\end{tabular}

Table 1: Determination of $\mathrm{pH}$.

\begin{tabular}{|l|c|c|}
\hline \multirow{2}{*}{ Samples } & $\mathbf{3 7}^{\mathbf{}} \mathbf{C}$ & $\mathbf{4 4}^{\mathbf{}} \mathbf{C}$ \\
\cline { 2 - 3 } & $\mathbf{C T} \mathbf{C F U} \mathbf{m L}$ & $\mathbf{C F} \mathbf{C F U} / \mathbf{m L}$ \\
\hline 1 & $2,1 \times 102$ & 42 \\
\hline 9 & 7 & 0 \\
\hline 10 & 5 & 0 \\
\hline 13 & $1,0 \times 103$ & $1,0 \times 103$ \\
\hline 14 & $1,0 \times 103$ & $1,0 \times 103$ \\
\hline 15 & 5 & $0,6 \times 102$ \\
\hline 16 & 51 & 5 \\
\hline 17 & 17 & 0 \\
\hline 18 & 12 & 0 \\
\hline 19 & $1,0 \times 103$ & 0 \\
\hline 20 & 12 & 0 \\
\hline 21 & $6,1 \times 102$ & $4,6 \times 102$ \\
\hline 22 & $6,4 \times 102$ & $1,7 \times 102$ \\
\hline 23 & $1,0 \times 103$ & $4,5 \times 102$ \\
\hline 24 & $1,0 \times 103$ & $4,6 \times 102$ \\
\hline 26 & 5 & 0 \\
\hline 28 & $1,0 \times 10$ & $6,6 \times 102$ \\
\hline
\end{tabular}

Table 2: Colony forming units (CFUs) of total and faecal coliforms per sample.

Some of the properties that determine that coliform bacteria are important in the alterations that food experiences are: 1 . Their ability to grower in very different substrates and to use as an energy source some carbohydrates and some other organic compounds and, as a source of nitrogen, some fairly simple nitrogen compounds; 2 . Your ability to synthesize the majority vitamins they need; 3 . The ability of bacteria in this group to grow perfectly within a fairly wide temperature range, from temperatures below $10 \mathrm{oC}$ to a temperature close to $46 \mathrm{oC} ; 4$. Your shell(d) to produce significant amounts of acid and gas from sugars; 5 . Your ability to produce unpleasant flavors, sometimes defined as "dirty"; 6. The ability to E. aerogenes to produce mucus or viscosity [15].

Escherichia coli is a bacillary microorganism, whose natural habitat is the faeces of man and some animals, reaching concentrations of $10^{9}$ bacteria per gram of faeces in humans. It is also called colibacilli, and in certain c as os can be pathogenic, causing intestinal disease (diarrhoea) and extra-intestinal disease (neonatal sepsis, urinary tract infections, pneumonia). Like all enterobacteria it has an intense biochemical activity, which has been used to make differential diagnosis with other species. It has the ability to fer- 
ment numerous carbohydrates, including lactose with acid and gas production. It is indole positive, does not use Citrate as a source of carbon nor hydrolyzes urea. Transmission of E. coli is caused by ingestion of water contaminated with faeces, contaminated food, lack of hygiene in food preparation or through flies [6].

Avila Pineda and cabbage (3) in his study refer to that of the 60 samples that analyzed the following percentages had counts above the stipulated values, $36.7 \%$ mesophils, $96.7 \%$ fungi and yeasts, $71.7 \%$ total coliforms in juice, and $23.3 \%$ faecal coliforms, and in terms of analismicrobiological water showed $55 \%$ of total coliforms and $20 \%$ of fecal coliforms above the norm. So did Martinez and cabbage. With the results obtained in 4 samples they managed to infer that $50 \%$ of the juices analyzed would taron Escherichia coli, 85\% of manipulators presented Staphylococcus aureus, 65\% of salads presented Listeria monocytogenes and $50 \%$ of meats presented Salmonella Spp. Concluding that pollution levels from these pathogens indicaten the high risk to the health of consumers by promoting the onset of foodborne diseases.

The results obtained from our study did not identify the presence of Escherichia coli in samples that had a foundation at

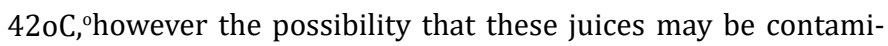
nated with some type of klebsiella bacteria that are género also thermotolerants is not ruled out.

Salmonella spp. produces Salmonellosis which is one of the most common and widely spread foodborne diseases, is estimated to affect millions of people worldwide annually and is generally characterized by high fever, abdominal pain, diarrhea, nausea and sometimes vomiting. Salmonella spp is a ubiquitous and resistant bacterium that can survive several weeks in a dry environment and several months in water [33].

The possible presence of this microorganism in artisanal juices may because the fruits are contaminated during cultivation, harvesting, transport and marketing, to their preparation since there are certain maneuvers that can introduce the microorganism such as slice, chopping or chopping, as well as the mapersonal hygiene practices or the use of unsuitable water [33].

Olvera Castelán [1] in her study found Escherichia coli and Salmonella spp with a frequency of approximately $20 \%$ and $15 \%$, respectively. The frequency and levels with which Thermotolerant Coliforms, Escherichia coli and Salmonella spp were isolated showed faecal contamination in juices as well as a high risk of sickness [1].

The sample whose result of biochemical tests gave us possible Salmonella spp (sample 13) was made an API-20E gallery (Figure) which is a standardized system, composed of a plastic strip with 20 wells containing different dehydrated substrates, used to identify enterobacteria.

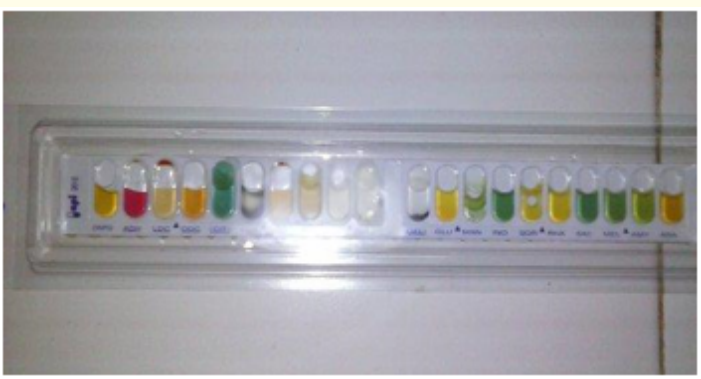

Figure a

The API- 20E gallery yielded a negative result for the possible Salmonella spp.

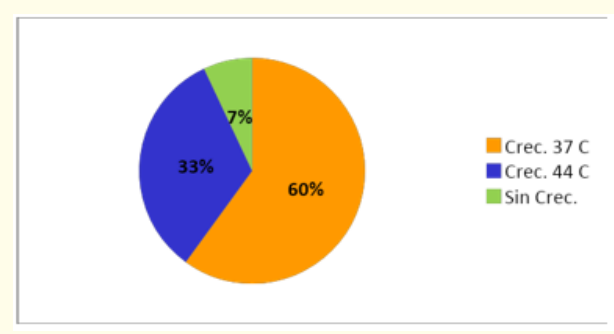

Figure 1: Coliform growth.

$100 \%(30 / 30)$ of juice samples that were incubated with MacConkey Agar resulted in growth in MacConkey Agar from $60 \%{ }^{\circ}(18 / 30)$ to $37 \mathrm{oC}, 33 \%(10 / 30)$ to $44 \mathrm{oC}^{\circ}$ and $7 \%(2 / 30)$ of samples showed no growth in that agar (Figure 1).

The first objective of incubation tests at different temperatures was the differentiation of coliforms of fecal origin from those that have no fecal origin. The group of fecal coliforms includes coliforms capable of growing at high temperature $\left(44^{\circ} \mathrm{C}\right.$ or $\left.45^{\circ} \mathrm{C}\right)$. 


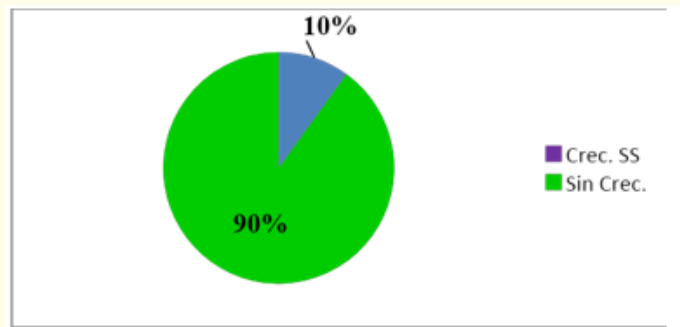

Figure 2: Growth in Salmonella-Shigella Agar.

On the other hand, $100 \%(30 / 30)$ of the juice samples that were sown in Salmonella-Shigella Agar resulted in the growth of $10 \%$ (3/30)of the samples, while 90\% (27/30) showed no growth in that agar (Figure 2).

SS Agar is a highly selective medium formulated to inhibit the growth of most coliform microorganisms and allow the growth of. Salmonella and Shigella speccies [31]. Table shows that of the samples sown in this agar (30 samples) growth of colorless colonies with black centers was observed, Salmonella Salmonella spp's presumptive in samples 13, 26 and 28 and the biochemical battery was made for identification resulting in samples 26 and 28 being negative for Salmonella spp; while sample 13 gave us a positive possible and for its full identification an API20E gallery was made.

\section{Conclusion}

The presence of various pathogenic microorganisms such as total and faecal coliforms in artisanal juices of frequent consumption in the schools Bioanalysis, Biomedical Sciences and Basic Area of the Faculty of Salt Sciences, suggests that the health quality of these actually poses a risk to the health of consumers. Improvements should be made to the processing, handling and storage of them so that they are free of microorganisms and do not pose a health risk. Similarly, the need for strict and constant health control that can ensure the safety of juices at the Faculty of Health Sciences is evident. This can only be achieved by integrating the education of the same traders and consumer awareness.

\section{Bibliography}

1. Olvera Castelán D. "Frequency and behaviour of Salmonella and hygiene indicator microorganisms in carrot juice". Autonomous University of the State of Hidalgo. Institute of Basic Sciences and Engineering. Mexico (2007): 3.
2. Astiasarán Anchía I and Martínez Hernández A. "Alimentos Composition and Properties". 1st Edition. Madrid, Spain. McGraw-Hill Publishing House (1999): 9.

3. Avila Pineda GT and Fonseca Moreno MM. "Microbiological quality of juices prepared in households of family well-being in the northern area of Cundinamarca. [Doctoral Thesis]". Bogota, D.C.: Pontificia Universidad Javeriana, Faculty of Sciences, Career in Industrial Microbiology (2008).

4. World Health Organization. Ata. Primary Health Care. Geneva (1978).

5. Ministry of Health. "Directorate General of Epidemiology, Nacional Network of Epidemiology". Epidemiological Bulletin. Number 50. Lima- Peru 21 (2012): 834.

6. González ML and González NM. "Manual of Micro Medical obiology". 2nd Edition. Directorate of Media and Publications of the University of Carabobo; Valencia- Carabobo State (2011): $179-183$.

7. Koneman EW., et al. "Microbiogóg ico diagnosis". Text and Atlas Color. 5th edition. Spain. Editorial Medica Panamericana (1999): 203.

8. Kopper G., et al. "Foodborne diseases and their socioeconomic impact". Case studies in Costa Rica, El Salvador, Guatemala, Honduras and Nicaragua. Technical report on agricultural and food engineering. Food and Agriculture Organization of the United Nations (FAO). Rome (2009): 140,141,160,164,165.

9. Mora D. "Human Consumption Water Situation and Excreta Assessment in Latin America and the Caribbean". Regional Meeting on Drinking Water Quality. Lima. CEPIS (1996).

10. Rafael Alvarez A. "Public Health and Preventive Medicine". 3rd edition. Mexico, D.F. Manual moderno S.A. de C.V. (2009): 179.

11. World Health Organization. "Guidelines for drinking water quality". 2nd edition. Recommendations. Geneva: World Health Organization 1 (1995): 3-6.

12. Rojas T and Castle Z. "Supervivencia of an isolate of Escherichia coli 0157:H7 in un pasteurized orange juices of commercial experience". Scientific Journal of the Venezuelan Society of Microbiology. Caracas - Venezuela (2003).

13. Alexander Gil A., et al. "Microbiological quality in fruit shells eattibles expendided in popular markets of the municipalities Valencia and San Diego, Carabobo State, Venezuela". Scientific Journal of the Venezuelan Society of Microbiology. Valencia Venezuela (2010). 
14. Rodríguez Rico II and Urbano Rivas MG. "Determination of the microbiological quality of refreshing beverages dispensed in fast food restaurant machines in district 1 of metropolitan San Salvador". University of El Salvador. San Salvador - El Salvador (2012).

15. Frazier WC and Westhoff DC. "Food Microbiology". 4th Edition. Editorial ACRIBIA, S.A. Zaragoza-Spain (1993): 72, 77, $89,259,260,261,263$.

16. Knight Torres Angel E. "Food Hygiene Topics". Editorial Medical Sciences. Habana-Cuba (2008): 34, 223, 224, 296.

17. Yeager S. "Medical Guide to Food Remedies: From avocado to carrots, nutrition experts reveal what you should eat to prevent and treat more than 100 diseases". Editorial Prevention. Spain (2001): 375, 451, 507, 508.

18. Raven Evert Eichhorn. "Plant Biology". Editorial Reverté, S.A. Barcelona - Spain (1992): 708.

19. Marquina V., et al. "Chemical composition and anti-ox capacity in fruit, pulp andguava jam (Psidium guajava L.)". [Research Work] Faculty of Pharmacy and Bioanalysis, Faculty of Medicine. University of Los Andes, Mérida - Venezuela (2008).

20. Baraona Cockrell M., et al. "Special Fruit Farming 5". 1st Edition. San Jose Distance State University Publishing House. Costa Rica (1992): 40.

21. Von Breymann J., et al. "Analysis of microbiological quality and potential presence of Listeria monocytogenes in soursop pulp (Annona muricata), mango (Mangifera indica) andmaracuyá (Passiflora edulis) Costa Rican". Center for Researchin Tropical Diseases and Faculty of Microbiology. University of Costa Rica (2003).

22. Martínez Salinas A., et al. "Manual of the Cultivation of the Castile Mora (Rubusglaucus B)". Ambato-Ecuador (2007): 4, 8, 9.

23. Galvis Murillo BS. "Study of the durability of the blackberry pulp of Castilla and Mora San Antonio (Rubus-Glaucus)". National University of Colombia Sede Marizales. Faculty of Engineering and Architecture. Chemical Engineering. [Doctoral Thesis]. Colombia (2003).

24. Ugarriza S. "Agricultural commercial terminology". Eucasa Editions of the Catholic University of Salta. Salta- Argentina (2009): 123.

25. García AD. "Physical and chemical characterization of peaches (Prunus pérsica (L) Batsch) and effectiveness of commercial rfrigeration in conditioned fruits". Biagro Magazine 18.2 (2006): 115-121.
26. Romero Cabello R and Herrera Benavente I. "Infectious Diarrhoeal Syndrome”. Pan American Medical Editorial. Mexico (2002): 96.

27. Hernández R., et al. "Methodology of Research". 4th edition. Editorial McGraw-Hill Interamericana. Mexico (2006).

28. Venezuelan Food Standard COVENIN 1126-89. "Food. Identification and preparation of samples for microbiological analysis".

29. Venezuelan Food Standard COVENIN 1315-79. Food. Determination of $\mathrm{pH}$. (Ionica acidity).

30. Venezuelan Food Standard COVENIN 1086-84. Food. Methods for Counting Coliform Bacteria in Petri Plates.

31. Washington C Winn., et al. "Microbiological Diagnosis". 6th Edition. Pan American Publishing House. Buenos Aires- Argentina (2008): 20, 24.

32. Prats G. "Medical Microbiology and Parasitology". Pan American Medical Editorial. Madrid - Spain (2013): 110.

33. Prats G. "Clinical Microbiology". Pan American Medical Editorial”. Madrid - Spain (2008): 26, 336

34. Betty A Forbes., et al. "Microbiology, Virology and Parasitology". 12th Edition. Pan American Publishing (2009).

35. MacFaddin. "Biochemical Tests for the Identification of Bacteria of Clinical Importance". 3rd Edition. Pan American Medical Editorial. Buenos Aires - Argentina (2003): 26, 201, 354, 357, 358.

36. Venezuelan Food Standard COVENIN 1291-88 "Food you. Salmonella Isolation and Identification". Salmonella.

\section{Assets from publication with us}

- Prompt Acknowledgement after receiving the article

- Thorough Double blinded peer review

- Rapid Publication

- Issue of Publication Certificate

- High visibility of your Published work

Website: www.actascientific.com/

Submit Article: www.actascientific.com/submission.php Email us: editor@actascientific.com

Contact us: +919182824667

Citation: Noja Izzeddin., et al. "Evaluation of Bacteriological Quality in Artisanal Juices Issued at Carabobo University. Faculty of Health Sciences. Bable Core". Acta Scientific Nutritional Health 5.1 (2021): 02-09. 